\title{
Генерация электромагнитных мод в сверхузкой нанощели, образованной серебряными поверхностями
}

\author{
$\underline{\text { А.К. Сарычев }}{ }^{*}$, А.В. Иванов \\ Институт теоретической и прикладной электродинамики Российской Академии Наук \\ *E-mail: sarychev_andrey@yahoo.com
}

DOI: 10.31868/RFL2020.24-25

Эффект плазмонной генерации электромагнитных полей в нанометровых масштабах представляется очень перспективным для создания новых оптических приборов, в частности, биологического и химического зондирования молекул [1]. Управляемые метаматериалы на основе плазмонных нанорезонаторах позволяют возбуждать усиленные электромагнитные поля на определенных частотах путем задания геометрии и пространственного расположения нанорезонаторов [2,3].

В нашей работе мы предлагаем генерацию колоссальных электромагнитных полей в сверхузкой нанощели, образованной гладкой и цилиндрической серебряными поверхностями (Рис.1).

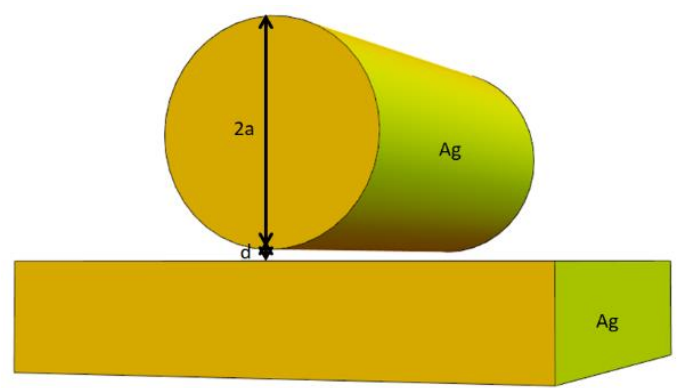

Рис.1 Серебряный цилиндр вблизи гладкой серебряной поверхности.

По мере сближения таких поверхностей в зазоре между ними возбуждаются щелевые электромагнитные моды, приводящие к резонансному усилению поля. Наиболее интересные эффекты возникают при почти касании цилиндра и плоской поверхности. Резонансные моды в таком щелевом резонаторе могут быть найдены в квазиклассическом приближении путем решения уравнения Лапласа, поскольку толщина зазора предполагается много меньше длины волны электромагнитного излучения. Электрическое поле, возбуждаемое падающим светом в зазоре между цилиндром и металлической поверхностью, раскладывается по щелевым модам и может найдено аналитически. Построена аналитическая теория, получающиеся ряды щелевых функций отсуммированы и найдено конечное выражение для электрического поля в зазоре. Полученное таким образом электрическое поле зависит длины волны, угла падения света и отношения толщины зазора $d$ к радиусу цилиндра $a$. В узкой щели, при условии $d \ll a$, поле сосредоточено на пространственном масштабе $l \sim \sqrt{a d},(d \ll l \ll a)$ и осциллирует как функция отношения $d / a$. Максимумы поля возникают, когда целое число щелевых мод укладывается на масштабе $l$.

На рис.2. представлена аналитически и численно рассчитанная зависимость усиления электрического поля как функция отношения ширины щели $d$, образованной двумя поверхностями, к радиусу цилиндра $a$ для длин волн возбуждения трех лазеров 405 нм, 532 нм, 785 нм. 


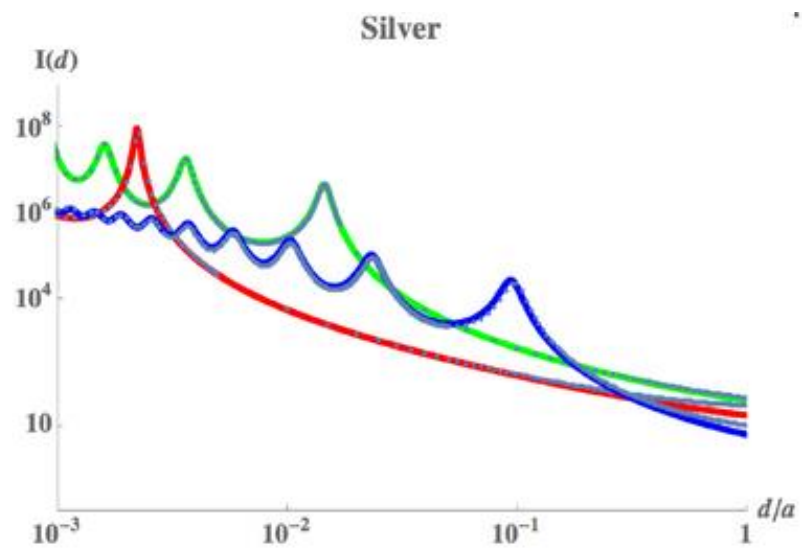

Рис.2 Относительная интенсивность электрического поля в зависимости от отношения ширины щели $d$ к радиусу цилиндру $a$. Синяя, зеленая и красная кривые соответствуют длинам волн 405 нм, 532 нм, 785 нм соответственно. Угол падения волны 45 градусов, поперечная поляризация электромагнитной волны. Точками обозначены численные расчеты.

Впервые теоретически показано, что по мере уменьшения отношения $d / a$ происходит рост резонансного усиления поля в зазоре между поверхностями вплоть до насыщения - когда концентрирующиеся моды начинают сливаться в зазоре. Интенсивность электрического поля в щели при насыщении соответствует значению более $10^{6}\left|E_{0}\right|^{2}$ при длине волны 405 нм, $10^{8}\left|E_{0}\right|^{2}$ при длине волны 532 нм и $10^{9}\left|E_{0}\right|^{2}$ при длине волны 785 нм, где $E_{0}$ это амплитуда электрического поля в падающем свете. Полученное гигантское усиление роля является важным для достижения рекордных значений и регистрации малых концентраций молекул методом гигантского комбинационного рассеяния. Такие щелевые резонаторы с контролируемой толщиной щели могут быть использованы для получения связанных состояний плазмона и колебаний молекул, помещённых в зазор. Обнаружение и исследование такого гибридного состояния позволит оценить и понять многие особенности гигантского комбинационного рассеяния и других плазмонных эффектов.

Данная работа поддержана Российским фондом фундаментальных исследований (РФФИ), грант № 20-21-00080.

\section{Литература}

[1] A.K. Sarychev, A. Ivanov et al, Materials 12, 103, 1-39 (2019)

[2] G. Barbillon, A. Ivanov, A.K. Sarychev, Nanomaterials 9, 1588, 1-12 (2019)

[3] G. Barbillon, A. Ivanov, A.K. Sarychev, Symmetry 12, 896, 1-16 (2020) 